\title{
A novel surgical approach to close an acute ventricular septal defect using an occluder device
}

Chanaka Rajakaruna, MRCS, Jonathan Hill, MA, MRCP, Eleanor Jane Holland Turner, BSc, PhD, MRCS, Alex Sirker, MRCP, Bushra S. Rana, MRCP, and Olaf Wendler, MD, PhD, FRCS, London, United Kingdom

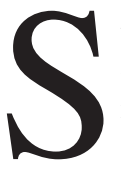

urgical treatment of an acute ischemic ventricular septal defect (aVSD) is still associated with high morbidity and mortality. We report a novel surgical procedure to close an aVSD.

\section{Clinical Summary}

A 75-year-old man with an acute anterior myocardial infarction was admitted to a peripheral hospital and transferred to our institution 4 days later with acute left heart failure and a grade 4 pansystolic murmur. On examination, he was tachypneic, with sinus tachycardia and a blood pressure of 100/82 $\mathrm{mm} \mathrm{Hg}$. The chest x-ray film showed signs of pulmonary edema. The echocardiogram confirmed an anterior VSD (diameter 7-9 $\mathrm{mm}$ ) with a left-to-right shunt (pulmonary/systemic [Qp/Qs] shunt ratio 3.4:1, measured with quantitative Doppler echocardiography). The right ventricle was of normal size and function and the estimated systolic pulmonary artery pressure (PAP) was $50 \mathrm{~mm} \mathrm{Hg}$ (Figure 1). The left ventricular ejection fraction was $45 \%$.

The patient's condition was stabilized with inotropic support and an intra-aortic balloon pump. Coronary angiography showed significant disease in the left anterior descending and right coronary arteries.

Ethical approval for this new approach was sought from the Novel Procedures Committee at our institution. After informed consent, the patient was taken to theater 10 days after admission because of worsening hemodynamics.

At operation ventricular function was found to be severely impaired. The patient was placed on cardiopulmonary bypass (CPB) with bicaval cannulation and revascularization was performed on the beating heart using a sequential internal thoracic artery to the left anterior descending and first diagonal branch and sequential vein grafts to the branches of the right coronary artery. An epicardial 3-dimensional echocardiogram showed the aVSD with a diameter of 18 by $21 \mathrm{~mm}$ in the mid septum. An attempt to insert the occluder device (Amplatzer; AGA Medical Corp, Golden Valley, Minn) into the aVSD via a puncture of the right ventricle failed owing to insufficient tactile feedback to the sur-

From the Departments of Cardiothoracic Surgery and Cardiology, King's College Hospital, London, United Kingdom.

Received for publication Aug 17, 2006; revisions received Sept 25, 2006; accepted for publication Oct 3, 2006.

Address for reprints: Mr Olaf Wendler, Clinical Director of Cardiology and Cardiothoracic Surgery, King's College Hospital, Denmark Hill, London SE5 9RS, United Kingdom (E-mail: olaf.wendler@kingsch.nhs.uk).

J Thorac Cardiovasc Surg 2007;133:579-80

$0022-5223 / \$ 32.00$

Copyright () 2007 by The American Association for Thoracic Surgery

doi:10.1016/j.jtcvs.2006.10.015 geon. Therefore, total CPB was established, ventricular fibrillation was induced, and the right ventricle was opened with a $2-\mathrm{cm}$ incision in the anterior wall directly above the aVSD. The aVSD showed a size of $20 \mathrm{~mm}$. An Amplatzer muscular occluder device of $24 \mathrm{~mm}$ (oversized by $10 \%$ to $20 \%$ as recommended by the manufacturer) was used. Because the deployment catheter of the device is produced for a percutaneous approach ( $1 \mathrm{~m}$ in length), the surgeon controlled the device at the tip of the guiding catheter and the first assistant controlled the end of the deployment catheter. After the device was deployed and its position confirmed (Figure 2), the right ventricle was closed with 4-0 Prolene polypropylene suture (Ethicon, Inc, Somerville, NJ) with pericardial pledgets. Retained air from the left and right sides of the heart was removed and the patient was weaned from CPB with intra-aortic balloon pump support and norepinephrine $\left(0.09 \mu \mathrm{g} \cdot \mathrm{kg}^{-1} \cdot \mathrm{h}^{-1}\right)$ infusion. Intraoperative echocardiography showed the device well seated across the aVSD, with residual flow through the center of the device.

The patient was extubated 12 hours after the operation and weaned from inotropic agents over the next 10 days. The patient's recovery was delayed by a right-sided hemothorax resulting from aspiration of a pleural effusion, which required chest drainage. He was subsequently discharged home mobilizing independently 32 days after the operation. His estimated PAP decreased to $30 \mathrm{~mm} \mathrm{Hg}$. The shunt size was calculated as 2:1 (Qp/Qs) at discharge. Now, at 6 months' follow-up, the systolic PAP was estimated to be $20 \mathrm{~mm} \mathrm{Hg}$, shunt size unchanged, and the patient was asymptomatic.

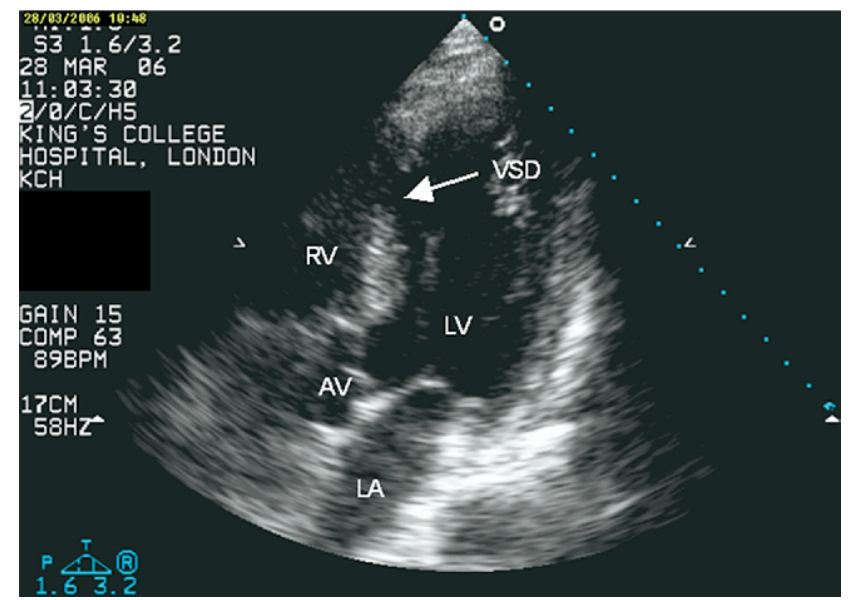

Figure 1. Five-chamber apical view showing site of ventricular septal defect (VSD). $L V$, Left ventricle; $L A$, left atrium; $R V$, right ventricle; $R A$, right atrium; $A V$, aortic valve. Markers on side of image are $1 \mathrm{~cm}$ apart. 


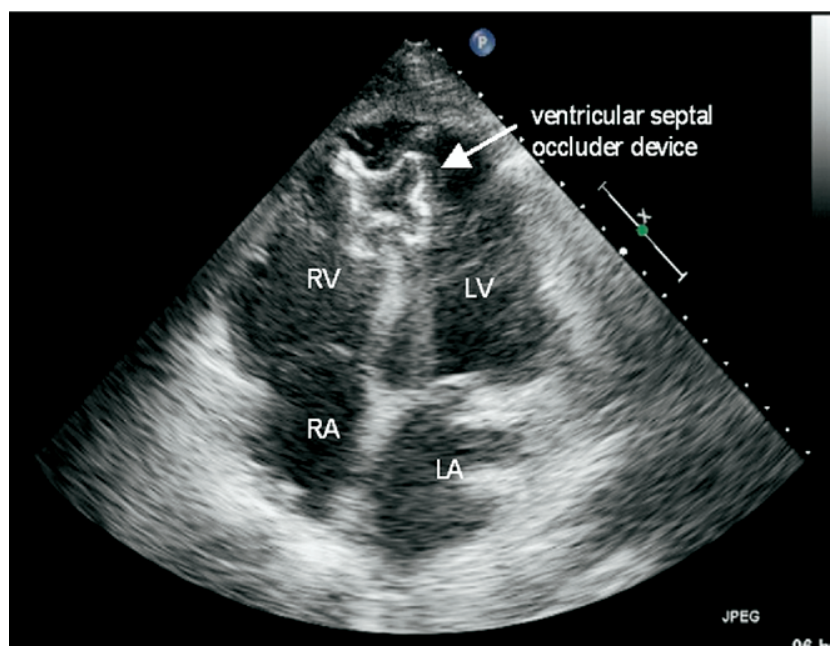

Figure 2. Four-chamber apical view showing position of ventricular septal occluder device in ventricular septum. $L V$, Left ventricle; $L A$, left atrium; $R V$, right ventricle; $R A$, right atrium.

\section{Discussion}

Postinfarction aVSD is an uncommon event that typically occurs during the first week after myocardial infarction and is associated with high morbidity and mortality with survivals of close to zero in conservatively managed cases. Early conventional surgery, usually performed with a prosthetic patch to close the VSD, has been shown to improve survival; however, even in selected patients in-hospital survivals are only around $50 \%$. $^{1}$

There is little in the literature concerning interventional approaches using an occluder device for postinfarction aVSDs, although use of such devices is a well-established method of closure for congenital defects. ${ }^{2-4}$ Holzer and associates ${ }^{4}$ reported promising results using percutaneously placed occluder devices in isch- emic VSDs in 18 patients; however, only 5 patients were treated in the acute setting, in which placement of the device was more complicated. ${ }^{4}$ Residual flow through the device has been previously reported and has been found to diminish over time owing to coagulation of blood in the device. ${ }^{5}$

This novel surgical approach is a new option in the treatment of aVSDs. An incision in the infarcted left ventricle is avoided, it can be performed on the beating heart to avoid further ischemia, and it allows placement of the device under direct vision. The limitation of this procedure is the persistent shunt through the device. It is suggested here that development of improved devices could result in even better outcomes. Possible techniques to deal with this residual flow could be the instillation of BioGlue (CryoLife, Inc, Kennesaw, Ga) into the device itself or securing a pericardial patch to cover the mesh on the right ventricular side of the device. Further cases are required to assess short- and long-term efficacy compared with conventional surgical closure before widespread use of this technique could be recommended.

\section{References}

1. Murday A. Optimal management of acute ventricular septal rupture Heart. 2003;89:1462-6.

2. Fu YC, Bass J, Amin Z, Radtke W, Cheatham JP, Hellenbrand WE, Balzer D, et al. Transcatheter closure of perimembranous ventricular septal defects using the new Amplatzer membranous VSD occluder: results of the U.S. phase I trial. J Am Coll Cardiol. 2006;47:319-25.

3. Carminati M, Butera G, Chessa M, Drago M, Negura D, Piazza L. Transcatheter closure of congenital ventricular septal defect with Amplatzer septal occluders. Am J Cardiol. 2005;96:52L-8L. Epub 2005 Nov 2.

4. Holzer R, Balzer D, Amin Z, Ruiz CE, Feinstein J, Bass J, et al. Transcatheter closure of postinfarction ventricular septal defects using the new Amplatzer muscular VSD occluder: results of a U.S. Registry. Catheter Cardiovasc Interv. 2004;61:196-201.

5. Michel-Behnke I, Le TP, Waldecker B, Akintuerk H, Valeske K, Schranz D. Percutaneous closure of congenital and acquired ventricular septal defects-considerations on selection of the occlusion device. J Interv Cardiol. 2005;18:89-99. 